\title{
放射線リレーの誤差解析 (I)
}

\section{最適時定数の決定}

\author{
小柳孝巳, 中嶋新一 \\ 新潟大学工学部精密工学科 \\ 長岡市学校町 1 丁目 \\ 1976年 5 月 26 日 受理
}

\begin{abstract}
放射線りレーを用いて，タンクの液位を定められた位置に停止する制御系に扣いて，放射線の統 計的変動により，液位の停止位置に䛊差を生ずる。これを最小にする方法について検討した。

結論は，放射線計数率計の時定数を適当に選択すればよいことがわかった。最適時定数を求める 式，計算結果を図扰よび表に示した。

最適時定数は上限用リレーと下限用リレーで異なる值となる。
\end{abstract}

\section{1. . まえがき}

Fig. 1 亿示す放射線リレーで水止弁を開閉し，液位 を希望位置に停止するリレー制御系において，放射線 の統計的変動のためにつぎの問題が生ずる。

1）液位が停止しているにもかかわらずりレーが動 作する。

2）液位が希望位置に達し、リレーが動作した直後 オン,オフ動作を繰り返す。

3）計数率計に含まれる時間おくれのために，液位 の变化より計数率計の出力の変化が沶くれる。乙 たがってリレー動作時刻がおくれる。

4）計数率計出力が統計的に変動し，したがってリ レーの動作時刻が変動する。

以上のような現象により, リレー動作時刻が液位に

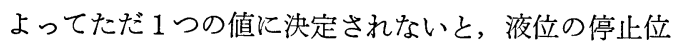
置も一定とならない。

これらの現象を解析して液位停止位置の誤差を，与 えられた範囲内に納める方法を見出すのが本研究の目 的である。

これらの問題のらち，1)については鶁見ら ${ }^{11}$ が液位 が上限で停止したのち, 放射線の統計的変動によっ て, 再度リレーが動作しないために必要な最小必要基 準率を求める方法を発表しており，現在用いられてい る。2)については，若林ら²)がリレーにヒシテリシス を付してチャタリングを防止する方法を示している。

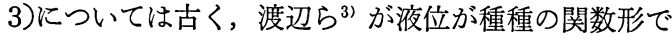
変化する場合の偏差を求めている。

4)については三輪ら4) が簡単にふれているが，他に

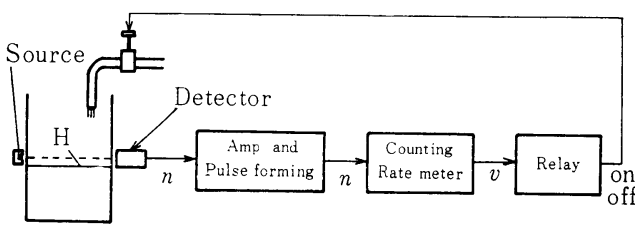

Iig. 1 Block diagram of level control system with radiation relay.

詳しい研究は発表されていないようである。この論文 では主としてこの第 4 の問題について研究した結果を のべる。この問題は適当な計数率計の時定数を決定す る問題に帰着する。

\section{2. 上限用リレー制御の動作}

Fig. 2 に液位 $H$, 検出器に入射する計数率 $n$, およ び計数率計出力 $v$ ，の関係を示す。検出器入射空は方

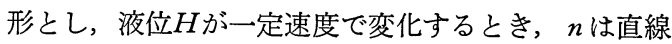
的に変化し, 液位が検出器空を覆ってしまうと一定の 最低值となる。 とすると，Fig. 2(c)のように初め上に凸形の曲線で減 少し, 液位が検出器空を覆ってしまう時刻 $T_{0}$ で变曲 点をもち，下に凸形の曲線となって最低值に漸近す る。 $v$ 曲線がリレーの動作レベルを横切る時刻にリレ 一が動作して液位は停止する。この研究ではリレーの 機械的，電気的誤差はないものとして話を進める。

$2 \cdot 1$ 計数率計の出力 $v$ の計算

Fig. 2 の関係を計算する。計数率計の伝達関数を

$$
G(s)=\frac{A}{1+T s}
$$




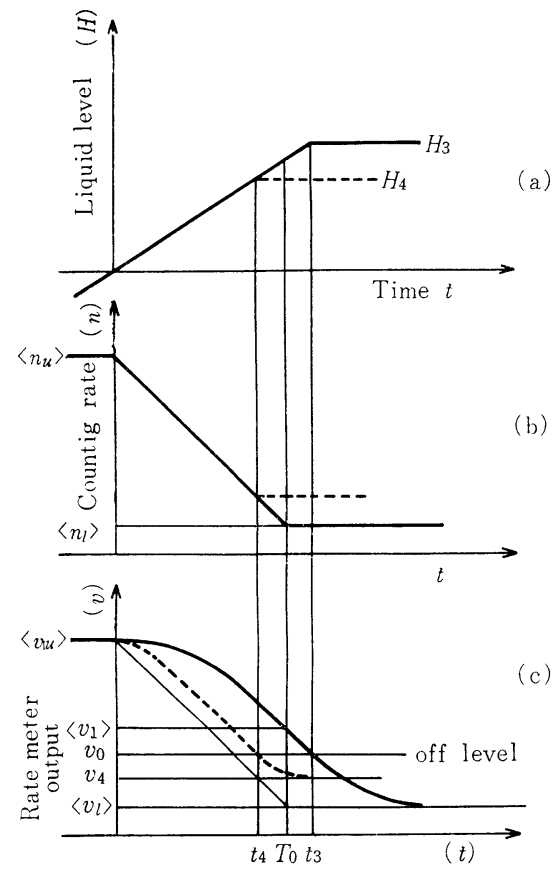

Fig. 2 Mutual relations of liquid level, counting rate and output of rate meter.

とする。定常状態では

$$
\langle v\rangle=A\langle n\rangle,\left\langle v_{u}\right\rangle=A\left\langle n_{u}\right\rangle
$$

となり，過渡状態ではつぎのようになる。

$$
\begin{aligned}
\frac{\langle v\rangle}{\left\langle v_{u}\right\rangle}= & 1-(1-k) \frac{T}{T_{0}}\left\{\operatorname { e x p } \left(-\frac{t}{T_{0}}\right.\right. \\
& \left.\left.\cdot \frac{T_{0}}{T}\right)-1+\frac{t}{T_{0}} \frac{T_{0}}{T}\right\}, \\
& 0<\frac{t}{T_{0}}<1 \\
\frac{\langle v\rangle}{\left\langle v_{u}\right\rangle}= & \left(\frac{\left\langle v_{1}\right\rangle}{\left\langle v_{u}\right\rangle}-k\right) \\
\cdot & \exp \left\{-\left(\frac{t}{T_{0}}-1\right) \frac{T_{0}}{T}\right\}+k, \\
& 1<\frac{t}{T_{0}}
\end{aligned}
$$

ただし $<v_{1}>$ は(2)式に沶いて $t / T_{0}=1$ と拈いた ときの $\langle v\rangle$ 值である。また $\left\langle v_{l}\right\rangle \mid\left\langle v_{u}\right\rangle=k$ と抒 き， $k$ は熟見らに従って透過係数とよぶ。

$T / T_{0}<1$ のときは<v>が<n>から特くれること がすくないから，液位が検出器空を全部覆わないらち にリレーが開き，液位の上昇が停止する。Fig. 2 の破 線にこれを示す。この場合は式はつぎのようになる。

$$
\begin{aligned}
\frac{\langle v\rangle}{\left\langle v_{u}\right\rangle} & =\left(\frac{v_{0}}{\left\langle v_{u}\right\rangle}-\frac{\left\langle v_{4}\right\rangle}{\left\langle v_{u}\right\rangle}\right) \\
& \cdot \exp \left\{-\left(\frac{t-t_{4}}{T_{0}}\right) \frac{T_{0}}{T}\right\} \\
& +\frac{\left\langle v_{4}\right\rangle}{\left\langle v_{u}\right\rangle}, \frac{t_{4}}{T_{0}}<\frac{t}{T_{0}}
\end{aligned}
$$

ただし $v_{0}$ はリレー動作レベル， $\left\langle v_{4}\right\rangle, t_{4}$ は Fig. 2 に示して㐫る。

(2)，(3)，（4)式に $k=0.1$ その他の数值を入れ て計算した結果を Fig. 3 亿示す。この場合 $v_{0}$ は熟見 らにならってつぎのように選んで抽く。

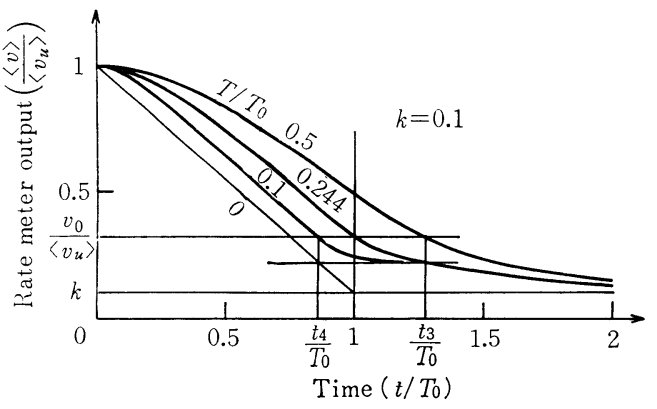

Fig. 3 Rate meter output of upper level control system. $v_{0} /\left\langle v_{u}\right\rangle=\sqrt{k}$

$$
\frac{\left\langle v_{u}\right\rangle-v_{0}}{v_{0}-\left\langle v_{l}\right\rangle}=\sqrt{\frac{\left\langle v_{u}\right\rangle}{\left\langle v_{l}\right\rangle}}=\sqrt{\frac{1}{k}}
$$

この関係から $v_{0} /<v_{u}>$ を計算すると

$$
\frac{v_{0}}{\left\langle v_{u}\right\rangle}=\sqrt{k}
$$

Fig. 3 を見ると $k=0.1$ のとき $T / T_{0}=0.2444$ の ときくv>が $t=T_{0}$ においてリレー動作レベルと交わ り，液位が停止する。 $T / T_{0}>0.2444$ のときは $\langle v>$ は $T_{0}$ よりおくれて， $t_{3}$ でリレーを動作させ，したが って液位は検出器空の上辺を越えて停止する。また

$T / T_{0}<0.2444$ のときは液位は検出器空の中間で停 止する。

\section{$2 \cdot 2$ 液位停止位置の誤差}

計数率計出力 $v$ に統計的変動がなければ，Tをどの ように選んでもリレー動作時刻は(2)，(3)，(4)式 から計算され，乙たがって液位停止位置も厳密に求め ることができる。しかしりには統計的変動がある。こ のためにvが v。 を横切る時刻は統計的に变動する。 この時刻の確率密度関数を求めれば, 液位停止位置の 分布が求められる。すなわち誤差がわかる。

この問題は確率過程において, 初期通過時刻密度関 
数を求める問題であるが, 厳密な計算は困難であるか らつぎの $2 つ の$ 仮定をもうけて液位停止位置の誤差を 概算する。

（1）Fig.4に示すように，雑音を含んだ電圧波形の 平均值が一定速度で降下するとき, 波形 作レベル voを横切る時刻の確率密度関数は, 雑音波 形の確率密度関数を時間軸上に投影したものとする。 この仮定は三輪ら ${ }^{4)}$ ，若林らなども用いている。
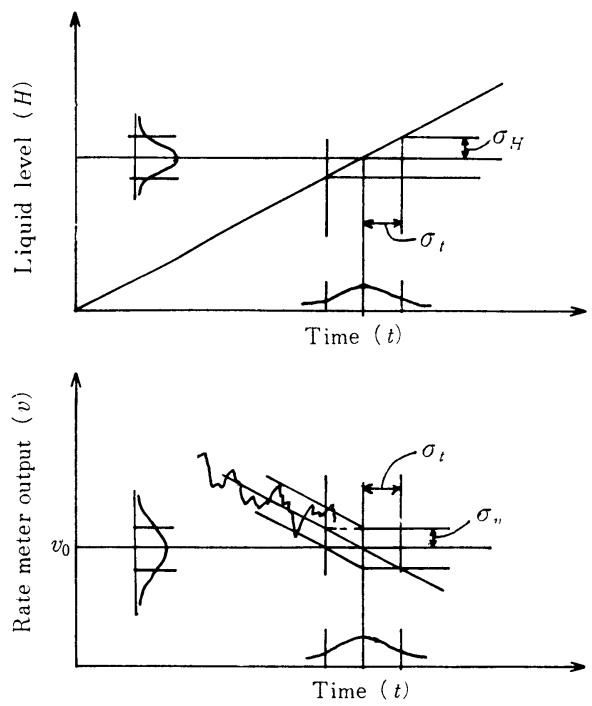

Fig. 4 Mutual relations of standard deviations of rate meter output $\sigma_{v}$, acting time of relay $\sigma_{t}$ and final liquid level $\sigma_{H}$.

（2）雑音を含んだ波形の雑音成分の標準偏差 $\sigma_{v}$ と, 波形の平均值 $\langle v\rangle$ との比は, 計数率計の伝達関数が 一定ならば, $1 / \sqrt{\langle v\rangle}$ に比例する。

(1)の仮定は事実とちがうが，この差異についてはべ つの機会に検討する。(2)の仮定は定常状態では正しい が，nが変化しつつあるときはちがう。これについて も詳しい検討は見られない。これはこの論文のあとで 検討する。

この 2 つの仮定をすると，Fig. 4 からつぎの関係が えられる。

$$
\begin{aligned}
& \frac{\sigma_{v}}{\sigma_{t}}=-\frac{d\langle v\rangle}{d t}, \frac{\sigma_{H}}{\sigma_{t}}=\frac{d H}{d t} \\
& \frac{\sigma_{H}}{\sigma_{v}}=\frac{d H}{d t} /-\frac{d<v\rangle}{d t} \\
& \frac{\sigma_{v}}{\langle v\rangle}=\frac{1}{\sqrt{2<n>T}}=\sqrt{\frac{A}{2 T}} \frac{1}{\sqrt{\langle v\rangle}}
\end{aligned}
$$

ここで

$\sigma_{v}$ : 計数率計出力vに含まれる雑音成分の標準偏差

$\sigma_{\mathrm{H}}$ : 液位停止位置の標準偏差

$\sigma_{t}:$ リレー動作時刻の標準偏差

これらの式から

$$
\begin{array}{r}
\sigma_{\boldsymbol{H}}=\frac{d H}{d t} \cdot \frac{\sigma_{v}}{-\frac{d<v>}{d t}}=\frac{d H}{d t} \\
\cdot \frac{1}{-\frac{d<v>}{d t}} \sqrt{\frac{A<v>}{2 T}}
\end{array}
$$

$\langle v>, t$ を正規化すると

$$
\begin{aligned}
\sigma_{H}= & \frac{d H}{d t} \sqrt{\frac{A T_{0}}{\left.2<v_{u}\right\rangle}} \times \sqrt{\frac{T_{0}}{T} \frac{\langle v\rangle}{\left\langle v_{u}\right\rangle}} \\
& -\left(\frac{d\left(\frac{\langle v\rangle}{\left\langle v_{u}\right\rangle}\right)}{d\left(\frac{t}{T_{0}}\right)}\right)
\end{aligned}
$$

$\frac{d H}{d t} \cdot \sqrt{\frac{A T_{0}}{\left.2<v_{u}\right\rangle}}$ を一定とすると， $\sigma_{H}$ は下の值に 比例する。

$$
\sqrt{\frac{T_{0}}{T} \frac{\langle v\rangle}{\left\langle v_{u}\right\rangle}} /-\left(\frac{d\left(\frac{\langle v\rangle}{\left\langle v_{u}\right\rangle}\right)}{d\left(\frac{t}{T_{0}}\right)}\right)
$$

リレー動作レベルに拈ける（8)式の值を計算してそ の最小值を与兄る $T / T_{0}$ の值を求めれば最適の $T$ が 決定される。

計算の順序としてはまず $k$ と $T / T_{0}$ を与えると， Fig. 3 に示すように<v>の曲線が(2)，(3)，(4)式 から定まる。したがってリレー動作レベル vo と淤け る(8)式の值が計算できる。

Fig. 3 に扮いて $\left\langle v>/\left\langle v_{u}>\right.\right.$ の曲線が $t / T_{0}<1$ に おいて $v_{0}$ と交わるときは(2)式から(8)式の值が計 算できる。

$$
-\frac{d\left(\frac{\left\langle v^{\prime}\right\rangle}{\left\langle v_{u}\right\rangle}\right)}{d\left(\frac{t}{T_{0}}\right)}=(1-k)\left\{1-\exp \left(-\frac{t}{T_{0}} \frac{T_{0}}{T}\right)\right\}
$$

$\frac{t_{4}}{T_{0}} \frac{T_{0}}{T}$ の值は(2)式に拈いて $<v>=v_{0}$ とお き，かつ(5)式から $v_{0} /\left\langle v_{u}\right\rangle=\sqrt{k}$ を用いて，

$$
\begin{aligned}
\frac{1}{1+\sqrt{k}}= & \frac{T}{T_{0}}\left\{\exp \left(-\frac{t_{4}}{T_{0}} \frac{T_{0}}{T}\right)\right. \\
& \left.-1+\frac{t_{4}}{T_{0}} \frac{T_{0}}{T}\right\}
\end{aligned}
$$

この式から求められる。(9)式の值と $\langle v\rangle /\left\langle v_{u}\right\rangle$ $=\sqrt{k}$ を( 8$)$ 式に代入すれば $k$ をパラメータとして 
$T / T_{0}$ と( 8 )式の値が計算できる。計算結果はここに は示さないが, $(8)$ 式の值は $k$ のあらゆる值において, ほ济， $\sqrt{T / T_{0}}$ に反比例する。すなわち $t / T_{0}<1$ で <v>が $v_{0}$ と交わるときは $T / T_{0}$ は大きいほど $\sigma_{H}$ が小さくなることがわかる。

ベつの面から考光ると, この場合は液位は検出器空 の中間で停止するから, 定常状態にはいってから誤動 作をする危険が増しよくない。

つぎに $\langle v\rangle /\left\langle v_{u}\right\rangle$ の曲線が $t / T_{0}>1$ に拈いて $v_{0}$ と交わるときはFig. 3 に批いて( 3 )式と $v_{0} /\left\langle v_{u}\right\rangle$ との交点で ( 8 )式の值を求めればよい。(2)式から $t /$ $T_{0}=1$ と执いて $\left\langle v_{1}\right\rangle /\left\langle v_{u}\right\rangle$ を求め, これを( 3 )式 に代入する。それを $t / T_{0}$ で微分し， $t=t_{3}$ に叔忛る 值を求める。 $t_{3}$ は $(3)$ 式に打いて $\langle v\rangle /\left\langle v_{u}\right\rangle=v_{0} /$ $\left\langle v_{u}\right\rangle=\sqrt{k}$ と执いて求められる。計算の結果はつぎ のようになる。

時刻 $t_{3}$ に和ける正規化された $\langle v>$ 曲線の傾斜は

$$
\begin{gathered}
-\frac{d\left(\frac{\langle v\rangle}{\left\langle v_{u}\right\rangle}\right)}{d\left(\frac{t}{T_{0}}\right)}=\frac{T_{0}}{T} \sqrt{k}(1-\sqrt{k}) \\
<v>=v_{0}
\end{gathered}
$$

これを(8)式に代入すると

$$
\sqrt{\frac{T}{T_{0}}} /(1-\sqrt{k}) \quad t / T_{0}>1
$$

となりこれは $\sqrt{T / T_{0}}$ に比例するから $T / T_{0}$ は小 さい汪どよいことになる。

以上 $2 つ$ 場合から<v>の曲線は $v_{0}$ に打いて変曲 点をもつように $T / T_{0}$ を選んだとき( 8$)$ 式の值が最 小になる。すなわち(2)式に拉いて $t / T_{0}=1,\langle v\rangle /$ $\left\langle v_{u}\right\rangle=\sqrt{k}$ と拈けば最適の $k$ と $T / T_{0}$ との関係を与 える式が求められる。

$$
\frac{\sqrt{k}}{1+\sqrt{k}}=\frac{T}{T_{0}}\left(1-e^{-T_{0} / T}\right)
$$

この関係を Fig. 5 和よびTable 1 に示す。

\section{3. 下限用リレー}

下限用リレーの場合はvは最低值 $\left\langle v_{l}\right\rangle$ から上昇 して $v_{0}$ に達したときリレーが動作して液位が停止す

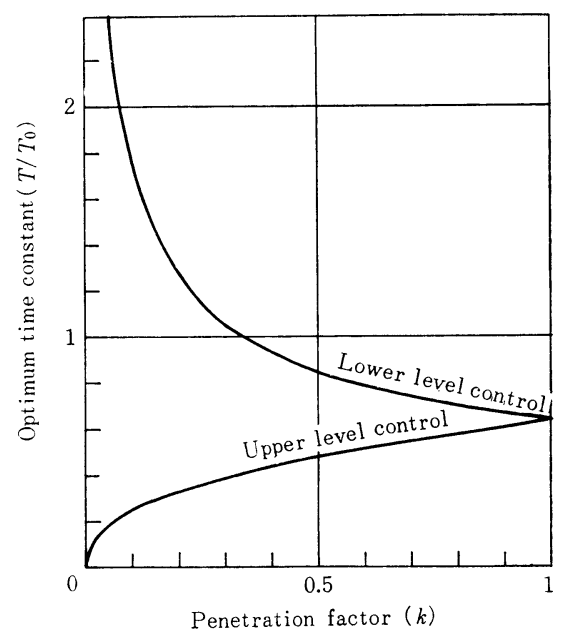

Fig. 5 Optimal time constant of counting rate meter. $v_{0} /\left\langle v_{u}\right\rangle=\sqrt{k}$

るが，vは計数率計に和けるおくれのためにさらに上 昇を続计最高值 $<v_{u}>$ に達する。最適の $T / T_{0}$ の値 は上限用リレーの場合之同様な計算により次式から求 められる。

$$
\frac{\sqrt{k}}{1+\sqrt{k}}=\frac{T}{T_{0}}\left(\frac{T_{0}}{T}-1+e^{-T_{0} / T}\right)
$$

この式で表される $T / T_{0}$ と $k$ との関係も Fig. 5 と Table 1 に示す。

最適值の場合の例を Fig. 6 亿示す。図では $k=0.1$, $T / T_{0}=1.732$ である。

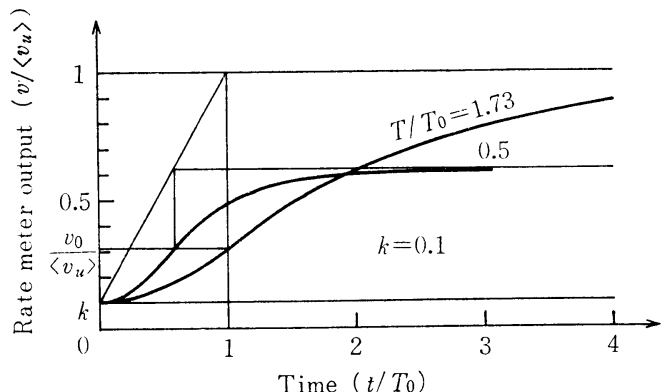

Fig. 6 Rate meter output of lower level control system. $v_{0} /\left\langle v_{u}\right\rangle=\sqrt{k}$

Table 1 Optimum value of $T / T_{0}$

\begin{tabular}{c|ccccccccccc}
\hline$k$ & 0.01 & 0.05 & 0.1 & 0.2 & 0.3 & 0.4 & 0.5 & 0.6 & 0.7 & 0.8 & 1.0 \\
\hline upper level & 0.091 & 0.18 & 0.24 & 0.32 & 0.38 & 0.43 & 0.47 & 0.51 & 0.54 & 0.57 & 0.63 \\
\hline lower level & 5.16 & 2.39 & 1.73 & 1.26 & 1.05 & 0.93 & 0.84 & 0.78 & 0.73 & 0.69 & 0.64 \\
\hline
\end{tabular}




\section{4. 仮定の検討}

$2 \cdot 2$ 項で設定した仮定について検討する。

(1)の仮定に関しては実験を行ってその結果を発表し たが6)，それによるとリレーの動作する時刻の平均值 は $\langle v\rangle$ 曲線と, $v_{0}$ との交点より進み, この進 又忚 $\langle v\rangle$ 曲線の傾斜が小さい汪ど大きい。分散も投影に よって求めたものと異なる。しかしこの進みは $T_{0}$ に 比べて大きくはないし，分散の変化も大きくない。し たがってこの現象に関してはさらに詳しい研究を行っ てその結果によって本研究の結果に補正を行えばよい と考えられる。

(2)の仮定については，つぎの極端な場合について検 討した。すなわち Fig. 7 (a)，(b) に示すように $<n>$ が 階段状に $<n_{u}>$ から零になった場合と，零から $<n_{u}>$ になった場合についてである。

さきの場合は，0<tでパルスははいらないからvに 雑音は含まれず， $t=0$ に抢けるvの初期值によって 定まる指数曲線をえがいて零に近づく。この部分にお いては

$$
\frac{\sigma_{v}}{\langle v\rangle}=\frac{\sigma_{u}}{\left\langle v_{u}\right\rangle}=\sqrt{\left.2 T \hat{\tau}_{\tau_{u}}\right\rangle}
$$

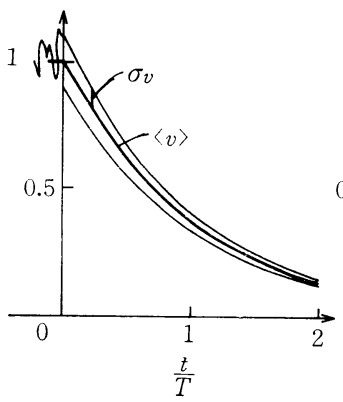

(a)

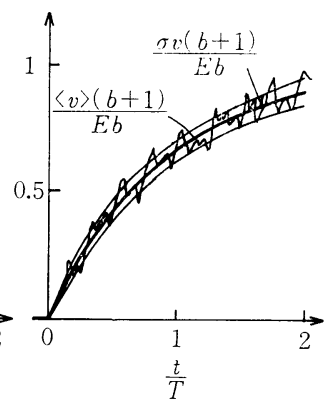

(b)
Fig. 7 Step response of rate meter.

となり $(7)$ 式のように $1 / \sqrt{\langle v\rangle}$ に比例しない。こ れは仮定と異なる。

一方 $<n>$ がゆっくり減少して零に近づく場合は過 渡状態に沶いても(7)式が近似的に成立すると考兄ら れる。すなわち， $<n>$ の变化のし方によって $\sigma_{v}$ $<v>$ の值は異なる。

$\langle v\rangle=v_{0}$ に和いて( 7)式と(15)式の值を比較する と, $v_{0}<<v_{u}>$ であるから(15)式の值のほうが小さ い。すなわち $<n>$ が最高値 $n_{u}$ から最低值零まで変 化する時間 $T_{0}$ に比べて，時定数 $T$ が大きいほど $v_{0}$ に郝ける $\sigma_{v} /<v_{0}>$ の值は小さくなる。しかしこの值
は最低限(15)式で与兄られる值より小さくはならな い。この值は $\sqrt{1 / T}$ に比例して減少する。一方 $\langle v>$ 曲線の傾斜は $T$ を増すと(11)式にしたがって1/Tに比 例して減少するから， $T / T_{0}$ には有限な最適値が存在 乙，その值は(13)式で与えられる値か，それより多少 大きい値と考兄られる。この $T / T_{0}$ の最適值の正確な 値の計算および実験も残さされた問題である。

つぎに $<n>$ が零から $<n_{u}>$ に変わった場合につい て検討する。この場合最初から $<n_{u}>$ は大きいが $<v>$ は初め小さくしだいに增加して最終值 $\left\langle v_{u}\right\rangle$ に 近づく。最終值では( 7 )式が成立するが，過渡部分で はどらであろらか。

これについては Schmilovsky，N.N．ら ら) の発表が ある。すなわち Fig. 8 に示す回路に階段的に平均值 $\langle n\rangle$ のパルス列が入射した場合の出力平均值 $\langle v\rangle$ と分散 $\sigma^{2}$ とは次式で与兄られる。

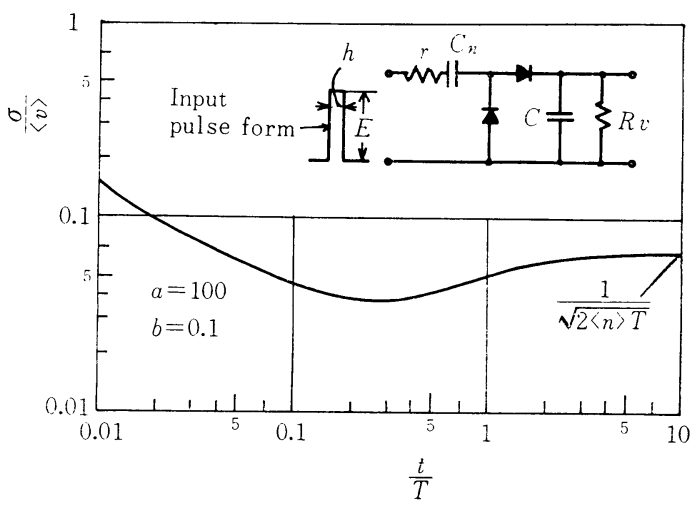

Fig. 8 Time transition of the ratio $\sigma /\langle v\rangle$. $\langle v\rangle$ : Mean value of $v$

$\sigma:$ Standard deviation of $v$ $\langle n\rangle$ : Input pulse rate

$$
<v>=\left(\frac{b E}{b+1}\right)\left\{1-\exp \left[-<n>t\left(\frac{b+1}{a+1}\right)\right]\right\}
$$

$$
\begin{aligned}
\sigma^{2}= & \left(\frac{b E}{b+1}\right)^{2}\left[\left(\frac{-2}{a+b+a b}\right) \exp \left\{-<n>t\left(\frac{b+1}{a+1}\right)\right\}\right. \\
& -\exp \left\{-<n>t\left(\frac{1+2 a+2 a b-b^{2}}{(a+1)^{2}}\right)\right\} \\
& +\frac{1}{2 a+2 a b-b^{2}} \\
& +\left\{\frac{(b+1)\left\{(a+1)\left(2 a+2 b-b^{2}\right)+(a-b)\right\}}{\left(2 a+2 a b-b^{2}\right)(a+b+a b)}\right\} \\
& \left.\cdot \exp \left\{-<n>t\left(\frac{2 a+2 a b-b^{2}}{a(a+2)}\right)\right\}\right]
\end{aligned}
$$

ただし $a=C R<n>=T<n>$

$$
b=C_{n} R\langle n\rangle=T_{n}\langle n\rangle
$$


$a \gg 1 \quad b \ll 1 \quad C_{n} R \ll h$

としてある。これらの関係からつぎの関係がえられ る。

$$
<n>t=\langle n>T t / T=a t / T
$$

また Fig. 8 の回路の伝達関数はつぎのようになる。

$$
G_{(s)}=\frac{\frac{b E}{b+1}}{1+\frac{T\left(\frac{a}{a}\left(\frac{1}{b+1}\right) s\right.}{1+T s}} \equiv \frac{b E}{1+T}
$$

いま $a=100, b=0.1$ のさの $\langle v\rangle(b+1) / b E$ と $\sigma(b+1) / b E$ を計算し Fig. 7 (b)に示す。また, $\sigma /\langle v\rangle$ を Fig. 8 に示す。これを見るとつぎのことがわかる。 $\sigma /\langle v\rangle$ の值は初め $1 / \sqrt{2 T<n>}$ より大きいが，乙 だいに減少し， $t / T=0.2$ くらいで最小值となる。こ のときの值は最終值の約 $1 / 2$ である。それ以後は増加し て最終値に達する。

すなわち(7)式よりもむしろ(15)式に近い傾向をも つ。このことは上限用リレーの場合, $\langle n\rangle$ が一定值 から階段的に零になった場合にも見られた。したがっ て下限用リレーも上限用リレーと同様な方法で最適な 時定数 $T$ が求められる。

\section{5. おわりに}

放射線リレーを用いてタンクの液位を定められた位 置に停止する制御系に执いて, 放射線の統計的変動の ために停止位置が一定とならない。この誤差を最小に する方法について検討した。

結論は, 計数率計の時定数を適当に選べばよいこと がわかった。その值は液位が放射線検出器入射空を通
過するに要する時間 $T_{0}$ と, タンクの放射線透過係数 $k$ によって定められる。

時定数 $T$ は上限用リレーと下限用リレーで異なる值 を用いねばならない。

計算式，計算結果を図および表に示した。

検出器に入射する放射線の計数率が变化しつつある 状態での計数率計出力の検討が残された問題である。

雑音を含んだ電圧の平均值が一定速度で变化してい く場合，その電圧によってリレーが動作する時刻を求 める問題は確率過程に和ける初期通過時刻の問題にな るが，この厳密な方法による解決は現在研 究中であ る。

以上の 2 つの不十分な点があるが，これらの点が解 明されたとしても，本論文の結論が否定されることは なく，多少の修正によってさらに精密な最適値がえら れる程度であると考えられるので，本研究を発表する こととした。

\section{文献}

1）熟見哲雄，諏訪志朗，制御工学，2，86 (1958)

2) 若林信生: 計測制御学会論文集, 11，45(1975)

3）渡辺 鐶：計測， 5, 21 (1955)

4) 三輪博秀：応用放射線計測，252, 日刊工業新 聞社, 東京 (1961)

5) N.N. Schmilovsky, et al.: 2nd Geneva Conf. A/CONF, 15, 2232 (1958)

6）小柳孝巳，他：第12回理工学にお汁る同位元素 研究発表会要旨集, 25 (1975)

\title{
Abstract
}

\section{Analysis of Errors of Radiation Relay (I). Optimum Setting of Time Constant}

\author{
Takami KoyAnAgI and Sinichi NAKajImA \\ Faculty of Engineering, Niigata University, \\ Gakko-cho, Nagaoka, Niigata Pref. Japan
}

The statistical error of liquid level controlled by radiation relay is analysed and a method of minimizing the error is proposed in this paper.

This method comes to the problem of optimum setting of the time constant of radiation relay. The equations for obtaining the value of time constant are presented and the numerical results are shown in a table and plotted in a figure.

The optimum time constant of the upper level control relay differs entirely from that of lower level control relay.

(Received May 26, 1976) 